Article

\title{
Antenna Mutual Coupling Suppression Over Wideband Using Embedded Periphery Slot for Antenna Arrays
}

\author{
Mohammad Alibakhshikenari ${ }^{1, *(\mathbb{D})}$, Bal S. Virdee ${ }^{2}$ (D) , Panchamkumar Shukla ${ }^{2}$, Chan H. See ${ }^{3}$ (i), \\ Raed Abd-Alhameed ${ }^{4}\left(\mathbb{D}\right.$, Mohsen Khalily ${ }^{5}$, Francisco Falcone ${ }^{6}$ (D) and Ernesto Limiti ${ }^{1}$ (D) \\ 1 Electronic Engineering Department, University of Rome Tor Vergata, Via del Politecnico 1, 00133 Rome, Italy; \\ limiti@ing.uniroma2.it \\ 2 Centre for Communications Technology, School of Computing and Digital Media, London Metropolitan \\ University, 166-220 Holloway Road, London N7 8DB, UK; b.virdee@londonmet.ac.uk (B.S.V.); \\ p.shukla@londonmet.ac.uk (P.S.) \\ 3 School of Engineering, University of Bolton, Deane Road, Bolton BL3 5AB, UK; c.see@bolton.ac.uk \\ 4 School of Electrical Engineering and Computer Science, University of Bradford, Richmond Rd, Bradford, \\ West Yorkshire BD7 1DP, UK; r.a.a.abd@bradford.ac.uk \\ 5 5G innovation Centre (5GIC), Institute for Communication Systems (ICS), University of Surrey, \\ Guildford GU2 7XH, UK; m.khalily@surrey.ac.uk \\ 6 Electric and Electronic Engineering Department, Universidad Pública de Navarra, 31006 Navarra, Spain; \\ francisco.falcone@unavarra.es \\ * Correspondence: alibakhshikenari@ing.uniroma2.it; Tel.: +0039-392-045-6365
}

Received: 20 August 2018; Accepted: 14 September 2018; Published: 16 September 2018

\begin{abstract}
This paper presents a new approach to suppress interference between neighbouring radiating elements resulting from surface wave currents. The proposed technique will enable the realization of low-profile implementation of highly dense antenna configuration necessary in SAR and MIMO communication systems. Unlike other conventional techniques of mutual coupling suppression where a decoupling slab is located between the radiating antennas the proposed technique is simpler and only requires embedding linear slots near the periphery of the patch. Attributes of this technique are (i) significant improvement in the maximum isolation between the adjacent antennas by $26.7 \mathrm{~dB}$ in X-band and $>15 \mathrm{~dB}$ in Ku and K-bands; (ii) reduction in edge-to-edge gap between antennas to $10 \mathrm{~mm}(0.37 \lambda)$; and (iii) improvement in gain by $>40 \%$ over certain angular directions, which varies between $4.5 \mathrm{dBi}$ and $8.2 \mathrm{dBi}$. The proposed technique is simple to implement at low cost.
\end{abstract}

Keywords: Mutual coupling suppression; slotted array antennas; synthetic aperture radar (SAR); Multiple-Input Multiple-Output (MIMO) systems; decoupling method

\section{Introduction}

Multiple-input multiple-output (MIMO) systems enable high-capacity wireless communications without increasing the signal bandwidth or signal-to-noise ratio (SNR). This is because the multiple data streams can be transmitted simultaneously by using multiple antennas (antenna array) at the transmitter and receiver. To realize compact MIMO antennas the critical challenge is to minimize the signal correlation between antennas over a wide frequency range. When multiple antennas are placed close the mutual coupling can degrade the radiation performances of the antennas and the channel capacity of MIMO systems.

Antenna size is determined mainly by its operating frequency, and therefore antennas occupy the largest space in wireless communication systems. Reducing the antenna size can be challenging 
as many factors need to be considered including size, weight, performance and cost of manufacture. Although array antennas based on microstrip integrated technology improve these factors; however, the strong mutual coupling between the adjacent antennas can severely degrade the antenna's performance in terms of gain, bandwidth and radiation pattern. It is evident in [1-3] that although the proximity of the radiating elements in MIMO satisfies the required compactness but this is at the cost of performance degradation.

To enable the widespread use of microstrip-based antenna arrays therefore requires the reduction of the mutual coupling between the array elements. In addition, to extend the beam scanning range of MIMO antennas, a smaller gap between antennas is necessary in the array to enable the scanning over a large angle. However, as the mutual coupling is predominantly strong in closely spaced antennas this can deteriorate the input impedance of each radiating element in the array to adversely affect the radiation efficiency and radiation pattern of the array [4,5].

Various techniques have been previously proposed to reduce the mutual coupling between adjacent elements in an antenna array including the use of cavity backed [6], substrate removal [7], defected ground structures (DGS) [8], metamaterial insulator [9], slotted complementary split-ring resonators [10], defected wall structure [11], and employing electromagnetic band gap (EBG) structures between two patches in microstrip antennas [12]. Although these techniques improve the reduction in mutual coupling however this is not enough for MIMO systems where compactness is required.

This paper presents a novel technique to reduce mutual coupling between adjacent radiating elements in an antenna array by increasing the isolation between the elements. Unlike conventional techniques where decoupling slab or DGS is inserted between neighbouring antennas in the array the proposed technique involves simply of embedding different lengths of slots near the outer most edge of the radiating patch. The proposed technique should enable the realization of highly dense antenna configuration with a reduced form factor which is necessary in SAR and MIMO communication systems. The resulting antenna array with the proposed technique is shown to exhibit significantly improved isolation between neighbouring patch elements ( $26.7 \mathrm{~dB}$ in X-band and $>15 \mathrm{~dB}$ in $\mathrm{Ku}$ and K-bands) and optimum gain performance (4.5-8.2 dBi) over certain angular directions. With the proposed technique the gap between the patches is reduced which should enable the design of a compact antenna array with the ability to scan over a larger angle.

\section{Proposed Slot Antenna for Antenna Arrays}

The reference array antenna is a $1 \times 2$ arrangement of rectangular microstrip patches, as shown in Figure 1a. Standard patch design was used to implement it on a standard FR-4 lossy substrate with dielectric constant of $\varepsilon_{r}=4.3, \tan \delta=0.025$, and thickness of $1.6 \mathrm{~mm}$. The performance of the antenna was verified using two commercially available 3D electromagnetic tools, namely, CST Microwave Studio $^{\circledR}$ (Darmstadt, Germany) and ANSYS High Frequency Structure Simulator (HFSS). The two patches are identical in size with dimensions of $25 \times 20 \mathrm{~mm}^{2}$ and edge-to-edge distance between radiation elements of $10 \mathrm{~mm}$.

The return-loss $\left(\mathrm{S}_{11}\right)$ and isolation $\left(\mathrm{S}_{12}\right)$ of the reference array are plotted in Figure 2. It's clear that, the reference antenna array covers three bands, i.e., $\mathrm{X}, \mathrm{Ku}$, and $\mathrm{K}$. To increase the isolation between elements in the array linear slots are embedded around the periphery of the patch, as illustrated in Figure 1b. Dimensions of the slot are given in Figure 1b, and the overall size of the array is given in Figure 1c. The return-loss and isolation response of the reference and proposed antenna array are shown in Figure 2. The average and peak mutual coupling improvement resulting from the proposed technique are $14 \mathrm{~dB}$ and $26.7 \mathrm{~dB}$ (X-band); $10 \mathrm{~dB}$ and $12.6 \mathrm{~dB}$ (first Ku-band); $13 \mathrm{~dB}$ and $>11 \mathrm{~dB}$ (second Ku-band); and $10 \mathrm{~dB}$ and $15 \mathrm{~dB}$ (third Ku-band and K-band). Tables 1-4 are given to facilitate comparison the maximum and average isolation of the reference and the proposed arrays over $\mathrm{X}, \mathrm{Ku}$ and K-bands, where the bandwidth is defined for $\left|S_{11} \leq-10 \mathrm{~dB}\right|$. It is also evident from the plots in Figure 2 that the slotted antenna array has a significantly better impedance match performance than the reference array. With the proposed technique the overall antenna design is simple, and the 
linear slots etched in the patch are easy to implement in practice, which thus reduces the overall manufacturing cost of the antenna array.

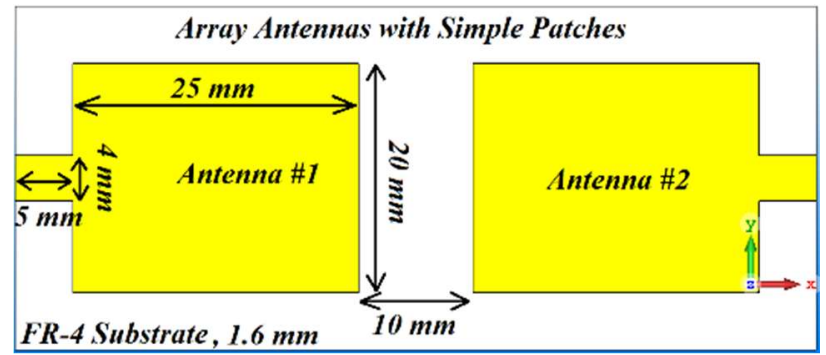

(a)

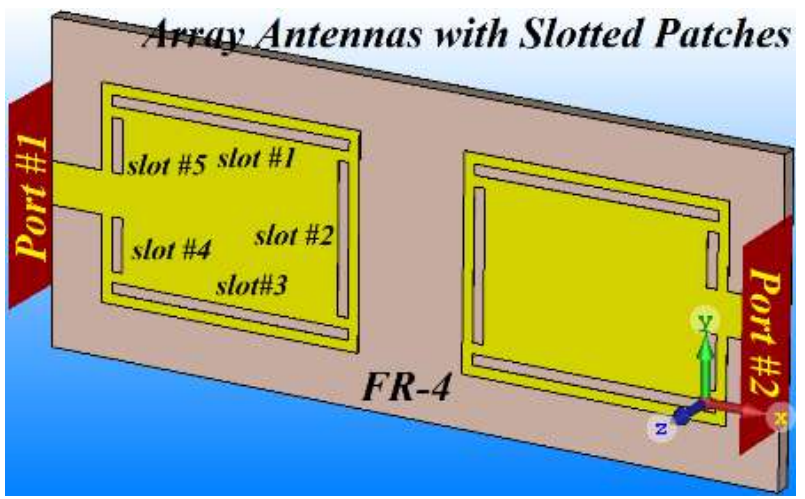

(b)

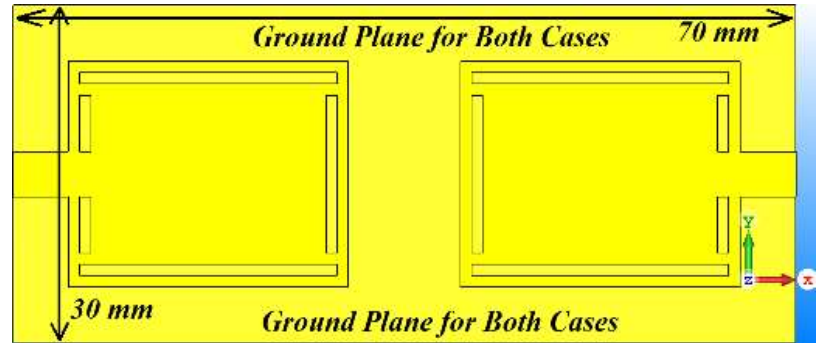

(c)

Figure 1. Array antenna prototypes (reference and proposed). (a) Simple reference array antenna; (b) Proposed slotted array antenna. Length of slots \#1 to \#5 are $23 \mathrm{~mm}, 14 \mathrm{~mm}, 23 \mathrm{~mm}, 5 \mathrm{~mm}$, and $5 \mathrm{~mm}$, respectively. Slot width is $1 \mathrm{~mm}$; (c) Ground plane for both simple and slotted arrays.

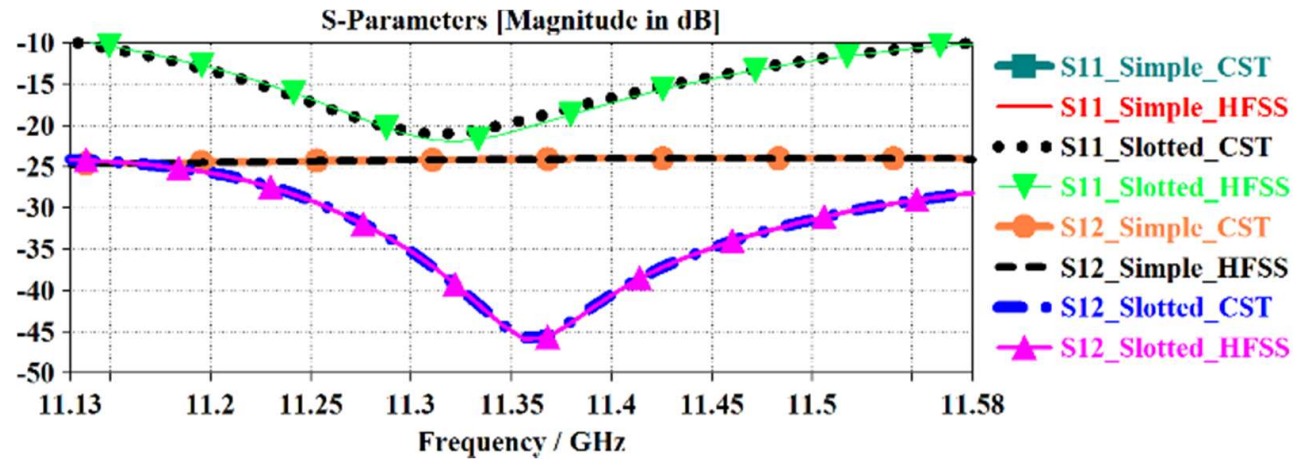

(a)

Figure 2. Cont. 


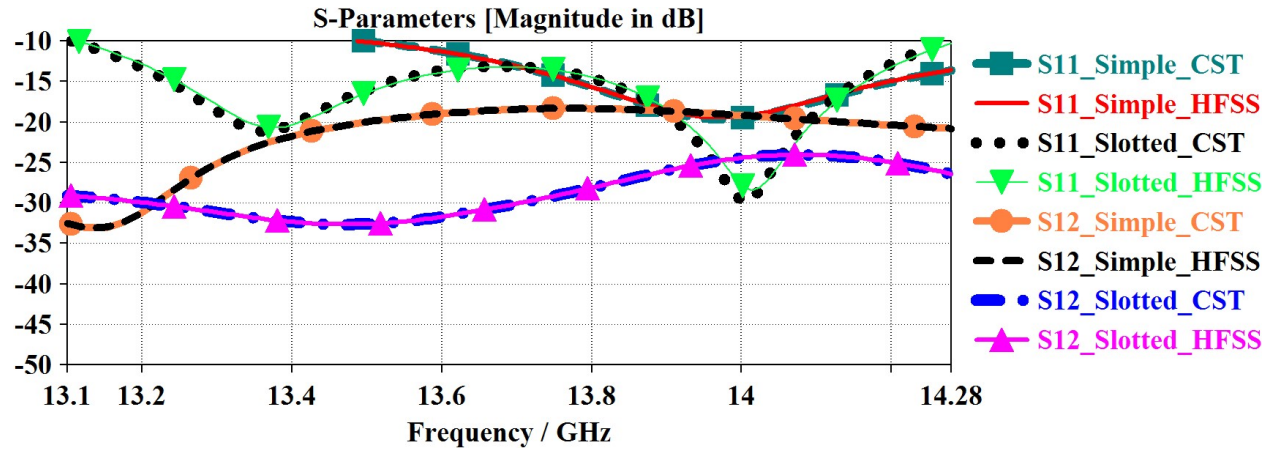

(b)

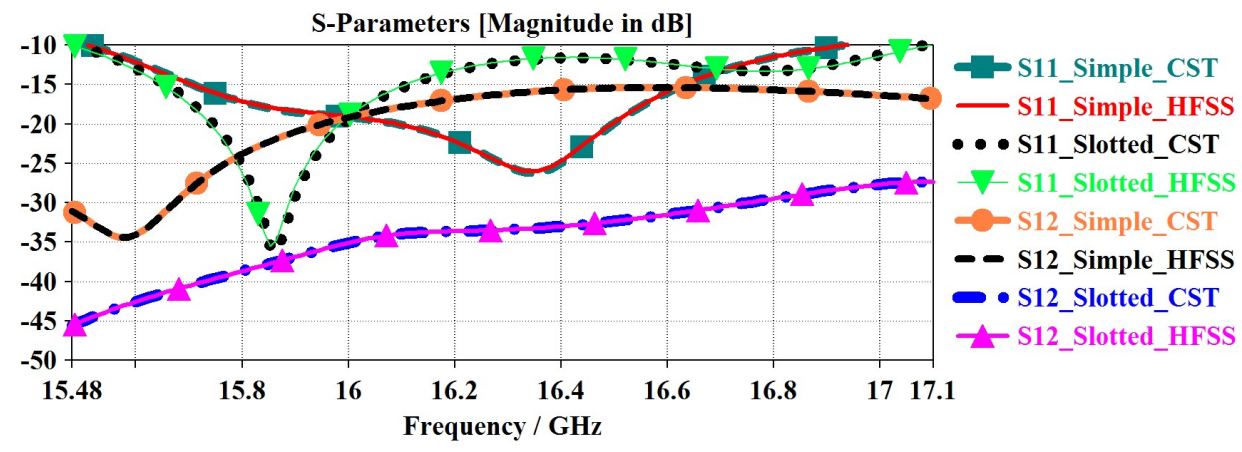

(c)

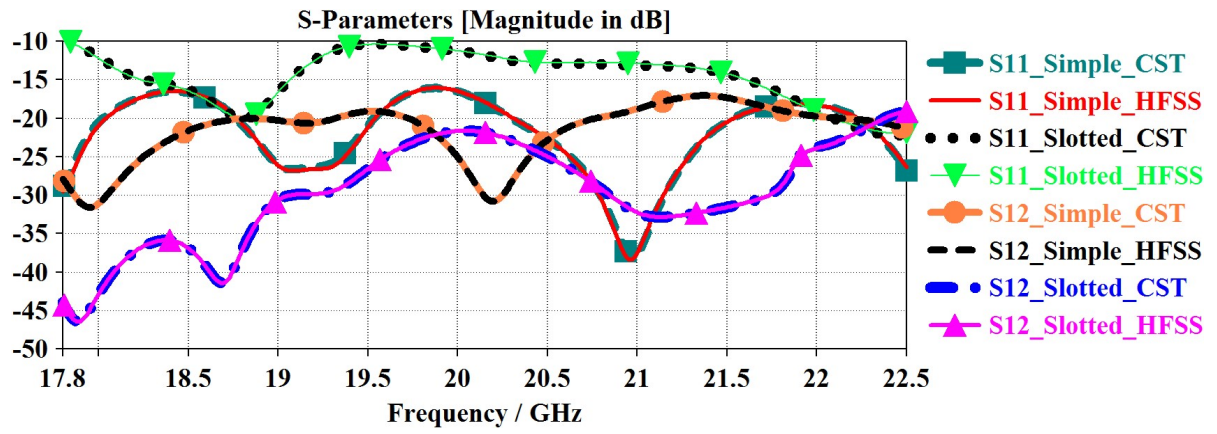

(d)

Figure 2. Reflection and transmision coefficients of the reference and proposed antenna array. (a) Coverage over X-band; (b) Coverage over the first Ku-band; (c) Coverage over the second Ku-band; (d) Coverage over the third Ku-band and K-band.

Table 1. Isolation in the X-band.

\begin{tabular}{ccc}
\hline \multicolumn{3}{c}{ First Band: 11.13-11.58 GHz $(\boldsymbol{\Delta f} \mathbf{~ = ~ 4 5 0 ~ M H z , ~ F B W ~ = ~ 3 . 8 8 \% ) ~}$} \\
\hline & Maximum & Average \\
\hline Reference Patch Antennas & $-24 \mathrm{~dB} @ 11.36 \mathrm{GHz}$ & $-24 \mathrm{~dB}$ \\
Slotted Patch Antennas & $-45.7 \mathrm{~dB} @ 11.36 \mathrm{GHz}$ & $-38 \mathrm{~dB}$ \\
Supression Improvement & $26.7 \mathrm{~dB} @ 11.36 \mathrm{GHz}$ & $14 \mathrm{~dB}$ \\
\hline
\end{tabular}

Table 2. Isolation in the first Ku-band.

\begin{tabular}{ccc}
\hline \multicolumn{3}{c}{ Second Band: 13.1-14.28 GHz $(\boldsymbol{\Delta f}=\mathbf{1 . 1 8 ~ G H z}, \mathbf{F B W}=\mathbf{8 . 6 2} \%)$} \\
\hline & Maximum & Average \\
\hline Reference Patch Antennas & $-20 \mathrm{~dB} @ 14.28 \mathrm{GHz}$ & $-19 \mathrm{~dB}$ \\
Slotted Patch Antennas & $-32.63 \mathrm{~dB} @ 13.56 \mathrm{GHz}$ & $-29 \mathrm{~dB}$ \\
Supression Improvement & $12.6 \mathrm{~dB}$ & $10 \mathrm{~dB}$ \\
\hline
\end{tabular}


Table 3. Isolation in the second Ku-band.

\begin{tabular}{ccc}
\hline \multicolumn{3}{c}{ Third Band: 15.48-17.1 GHz $(\boldsymbol{\Delta f}=\mathbf{1 . 6 2 ~ G H z , ~ F B W ~ = ~ 9 . 9 5 \% ) ~}$} \\
\hline & Maximum & Average \\
\hline Reference Patch Antennas & $-34.4 \mathrm{~dB} @ 15 \mathrm{GHz}$ & $-24 \mathrm{~dB}$ \\
Slotted Patch Antennas & $-45.6 \mathrm{~dB} @ 15 \mathrm{GHz}$ & $-37 \mathrm{~dB}$ \\
Supression Improvement & $>11 \mathrm{~dB} @ 15 \mathrm{GHz}$ & $13 \mathrm{~dB}$ \\
\hline
\end{tabular}

Table 4. Isolation in the third Ku-band and K-band.

\begin{tabular}{ccc}
\hline \multicolumn{3}{c}{ Fourth Band: 17.8-22.5 GHz $(\boldsymbol{\Delta f}=\mathbf{4 . 7} \mathbf{G H z}, \mathbf{F B W}=\mathbf{2 3 . 3 2} \%)$} \\
\hline Maximum & Average \\
\hline Simple Patches & $-31.6 \mathrm{~dB} @ 17.9 \mathrm{GHz}$ & $-24 \mathrm{~dB}$ \\
Slotted Antennas & $-46.4 \mathrm{~dB} @ 17.9 \mathrm{GHz}$ & $-34 \mathrm{~dB}$ \\
Supression Improvement & $15 \mathrm{~dB} @ 17.9 \mathrm{GHz}$ & $10 \mathrm{~dB}$ \\
\hline
\end{tabular}

The input impedance and admittance of the proposed slotted antenna array its operating range using circuit model and CST Microwave Studio ${ }^{\circledR}$ are shown in Figure 3. There is very good correlation in input impedance and admittance responses between the circuit model and CST Microwave Studio ${ }^{\circledR}$.

Surface current distribution over the reference and the slotted antenna array are shown in Figure 4. It is evident from these figures the slots behave as a decoupling structure that soak up the surface waves that would otherwise couple with the adjacent radiating elements.
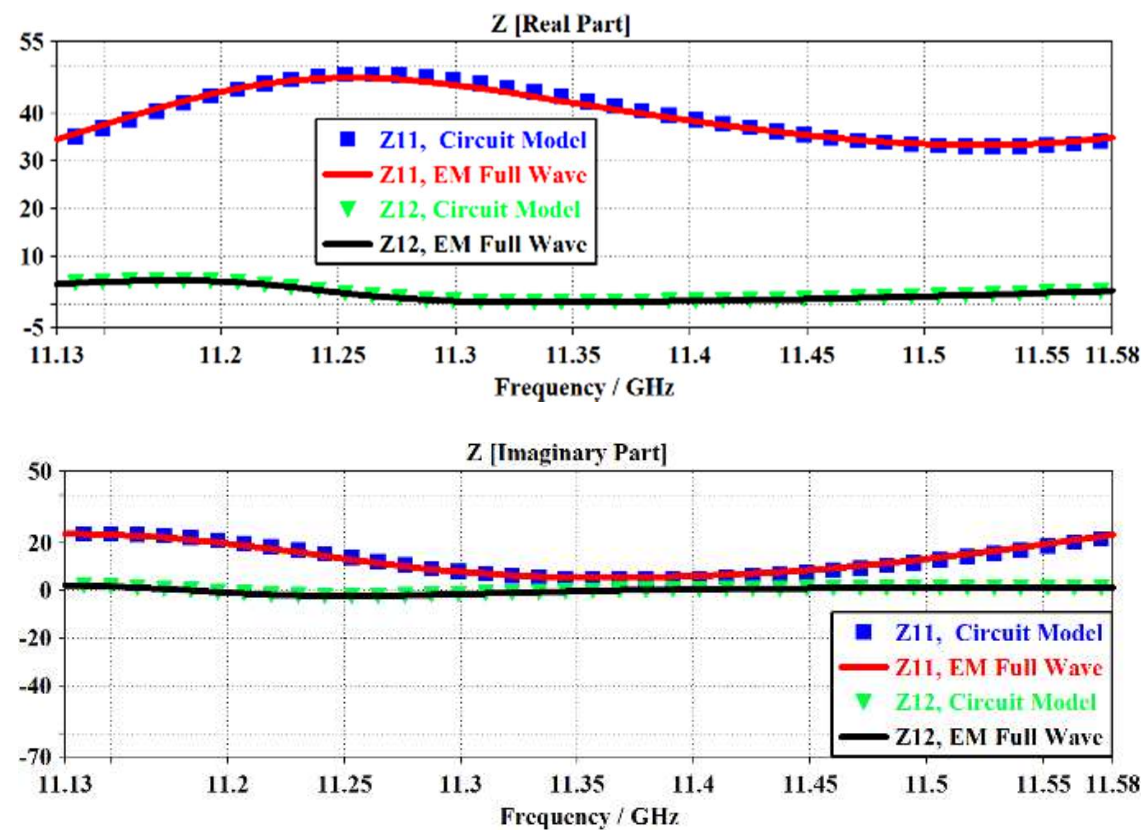

(a)

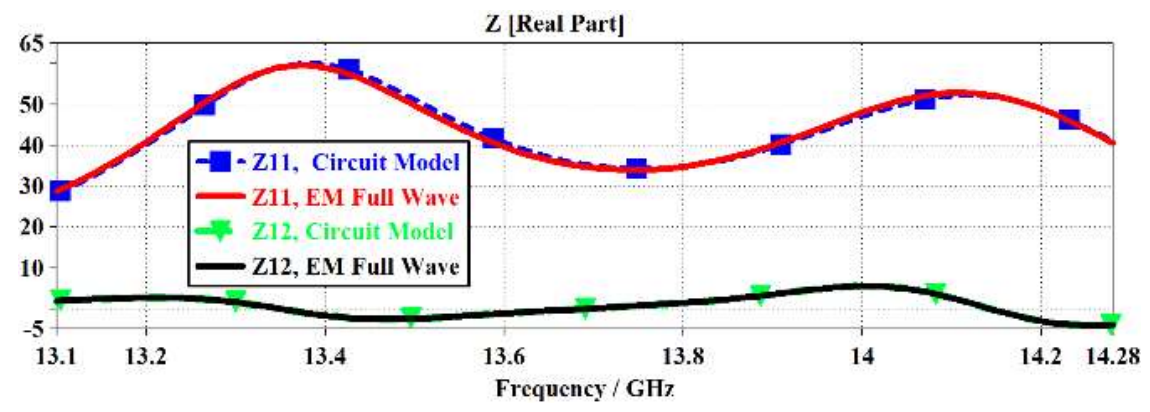

Figure 3. Cont. 


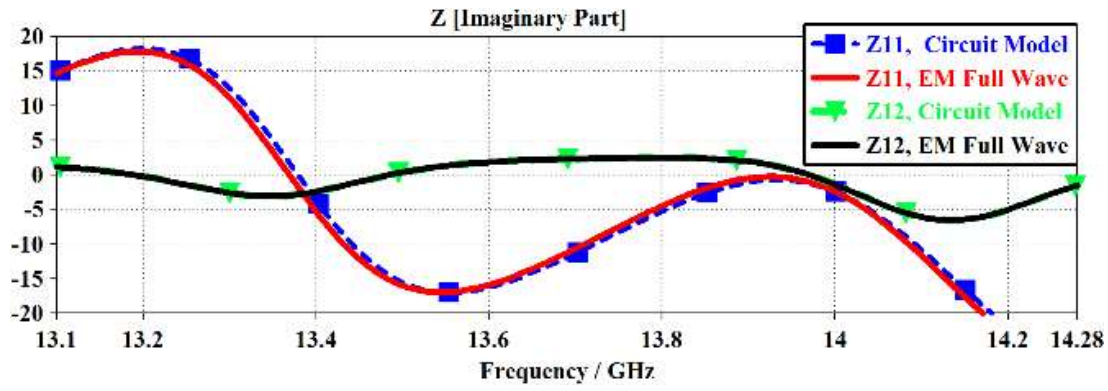

(b)
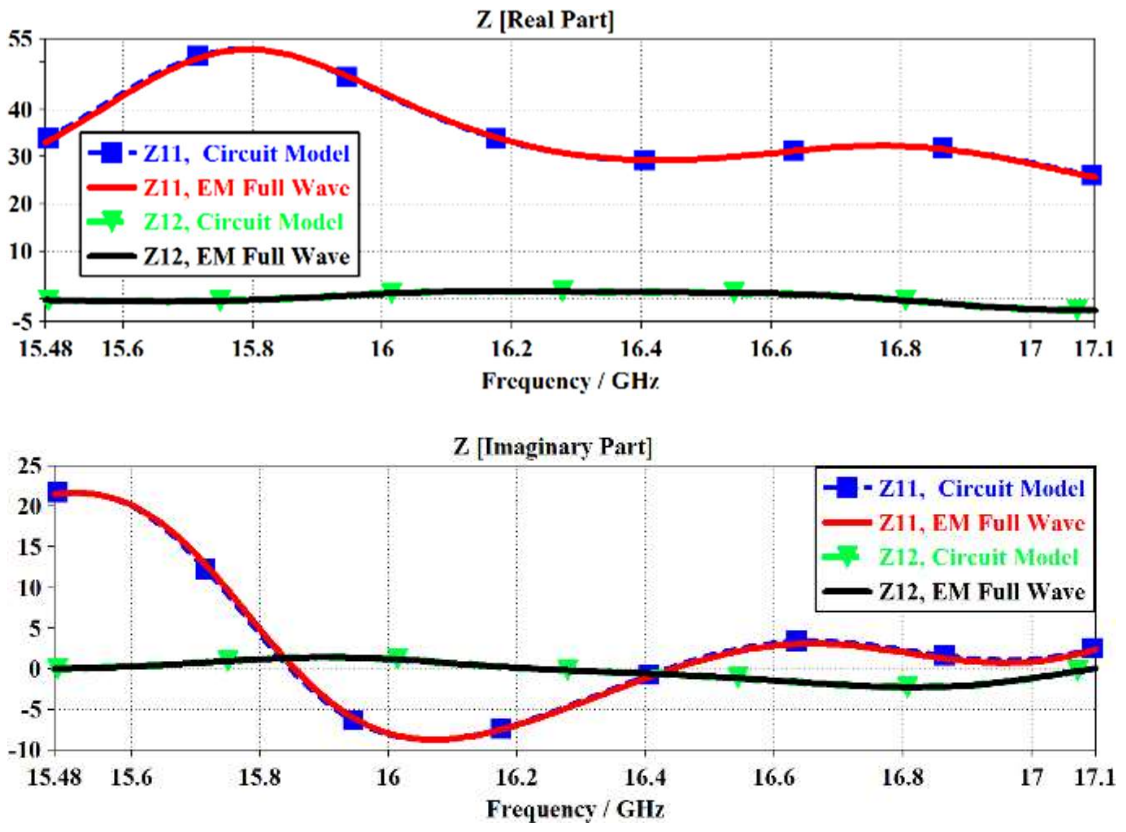

(c)
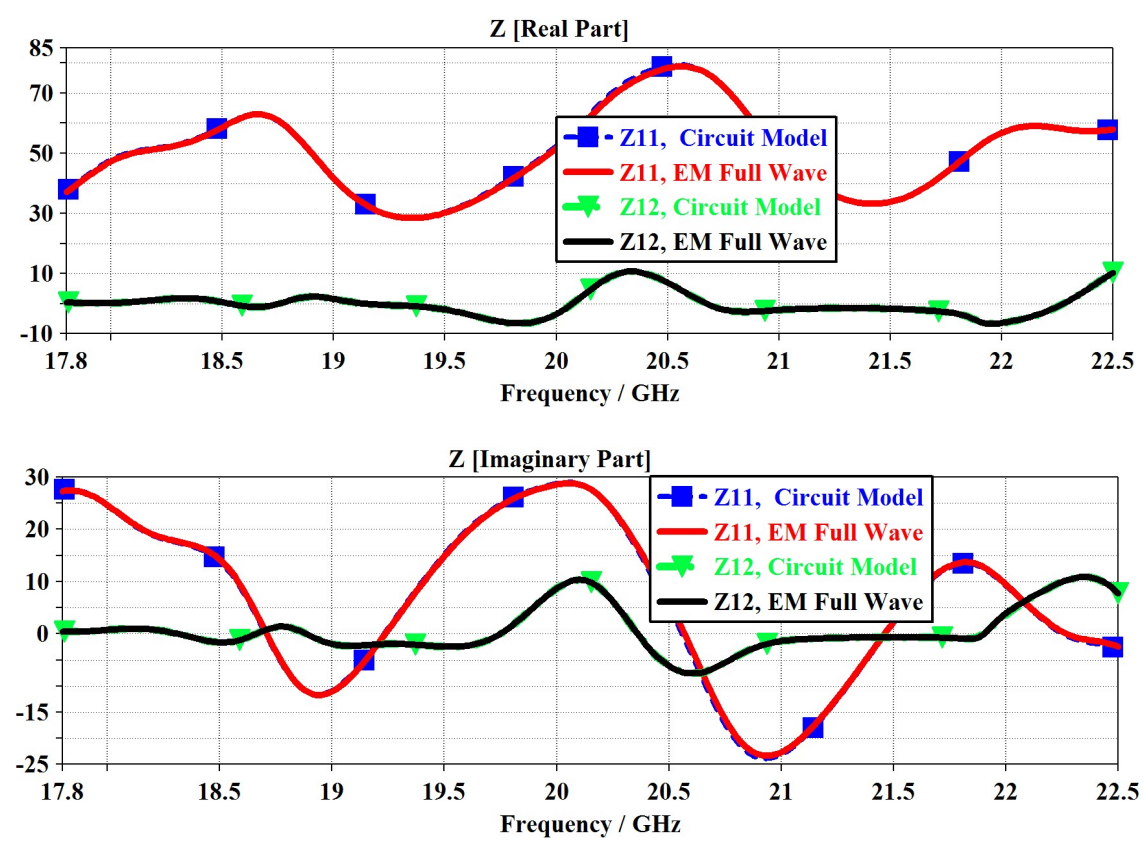

(d)

Figure 3. Input impedance $(\Omega)$ and admittance $(1 / \Omega)$ of the proposed slotted array antenna. (a) Coverage over X-band; (b) Coverage over the first Ku-band; (c) Coverage over the second Ku-band; (d) Coverage over the third Ku-band and K-band. 


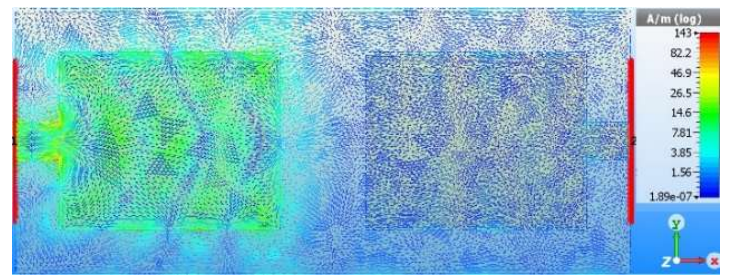

Port \#1 excited

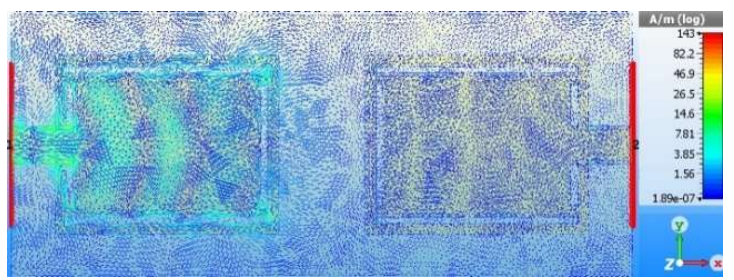

Port \#1 excited

(b)

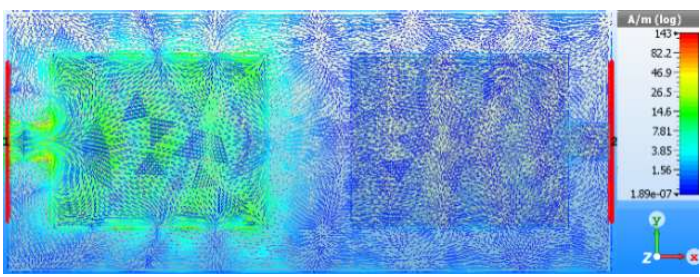

Port \#1 excited

(c)

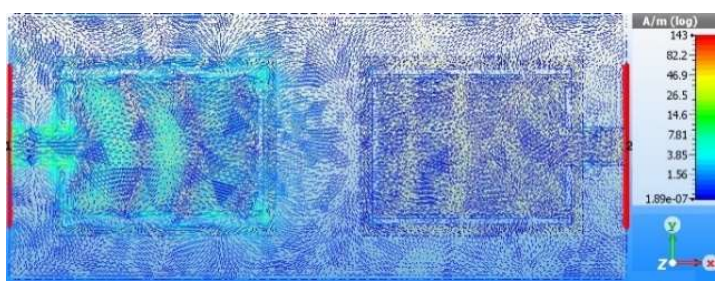

Port \#1 excited

(d)

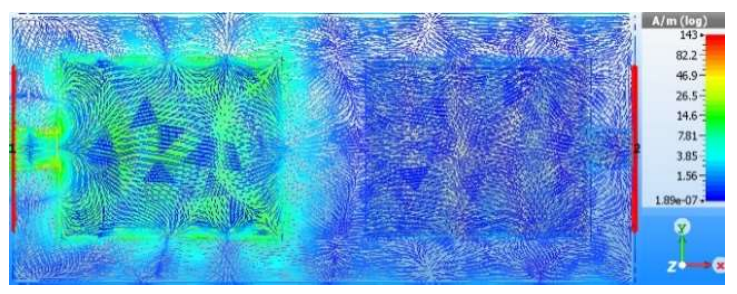

Port \#1 excited

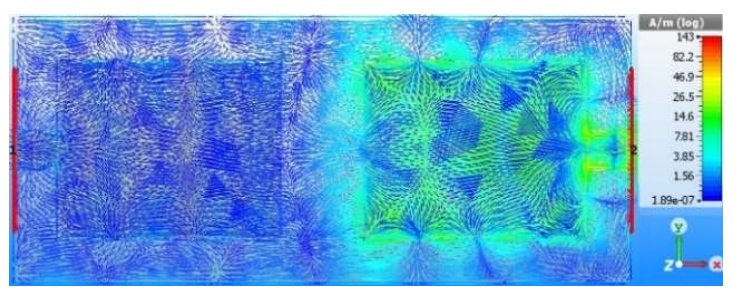

Port \#2 excited

(e)

Figure 4. Cont. 


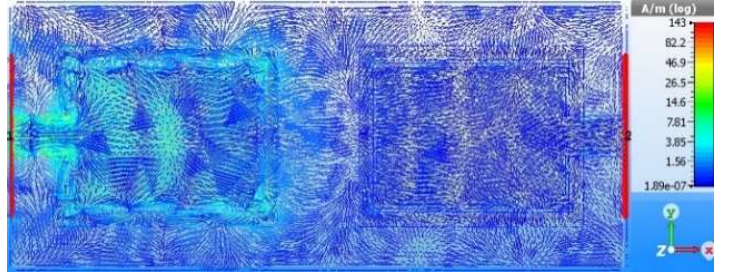

Port \#1 excited

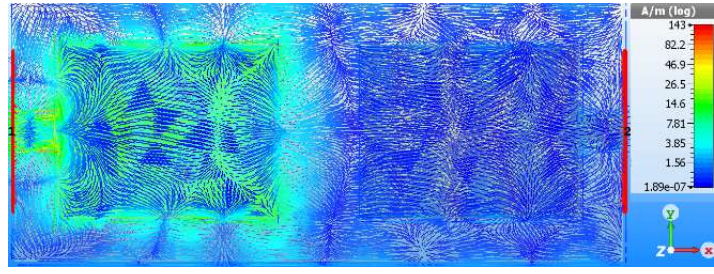

Port \#1 excited

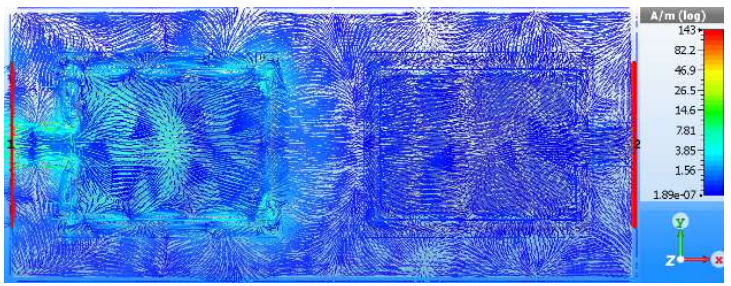

Port \#1 excited

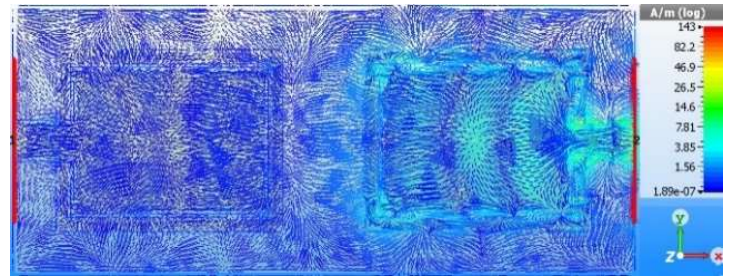

Port \#2 excited

(f)

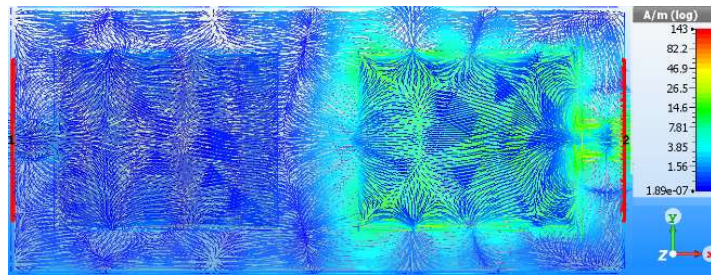

Port \#2 excited

$(\mathrm{g})$

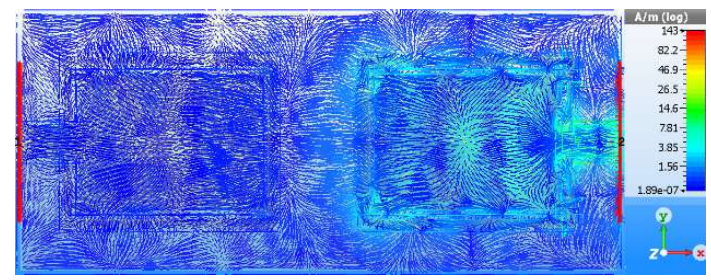

Port \#2 excited

(h)

Figure 4. Surface current distribution over the reference and slotted arrays. (a) Reference Array@ 11.37 GHz in X-band; (b) Proposed Slotted Array@11.37 GHz in X-band; (c) Reference Array@ 13.6 GHz in Ku-band; (d) Proposed Slotted Array@ 13.6 GHz in Ku-band; (e) Reference Array@ 15.9 GHz in Ku-band; (f) Proposed Slotted Array@ 15.9 GHz in Ku-band; (g) Reference Array@ 18.7 GHz in K-band; (h) Proposed Slotted Array@ 18.7 GHz in K-band.

Radiation patterns of the simple reference (Sim.) and proposed slotted (Slo.) antenna arrays in the horizontal $(\mathrm{H})$ and vertical $(\mathrm{V})$ planes are shown in Figure 5. After applying the proposed slots to the patch array the radiation pattern in the H-plane is distorted with large variation in the radiation pattern. Over certain angular directions the array exhibits better gain performance than others. At $11.3 \mathrm{GHz}$ the gain varies from $5.9 \mathrm{dBi}$ to $8.2 \mathrm{dBi}$, and at $15.9 \mathrm{GHz}$ it varies from $3.1 \mathrm{dBi}$ to $4.5 \mathrm{dBi}$.

The performance of the proposed technique is compared with other mutual coupling reduction mechanisms in Table 5. Application of decoupling slab between the array elements is a popular conventional technique. Although this results in reducing mutual coupling it does not contribute in reducing the overall size of the array. It is demonstrated here that the proposed technique provides a simple solution of both reducing the surface currents and therefore enhancing the isolation between neighbouring radiators, and overall size reduction, but further work is needed to improve its radiation characteristics. The proposed method offers an average and maximum isolation between transmit and receive antennas of $\sim 15 \mathrm{~dB}$ and more than $>26 \mathrm{~dB}$, respectively, over a narrow angular range which is better than other techniques. The advantage of the proposed technique is its simplicity. 
Table 5. Comparison between the proposed array with the recent works.

\begin{tabular}{|c|c|c|c|c|c|c|c|c|c|c|}
\hline Ref. & Method & $\begin{array}{l}\text { Dimenssions } \\
\text { in } \mathrm{mm}^{3}\end{array}$ & $\begin{array}{c}\text { Max. } \\
\text { Isolation }\end{array}$ & Bandwidth & Bands & $\begin{array}{l}\text { Reduction in } \\
\text { Bandwidth }\end{array}$ & $\begin{array}{l}\text { Rad. Pattern } \\
\text { Deterioration }\end{array}$ & $\begin{array}{c}\text { No. of } \\
\text { Elements }\end{array}$ & $\begin{array}{c}\text { Use of } \\
\text { DGS }\end{array}$ & $\begin{array}{c}\text { Edge-to-Edge } \\
\text { Gap }\end{array}$ \\
\hline [12] & EBG & $6.8 \times 5 \times 1.92$ & $8.8 \mathrm{~dB}$ & Narrow & Single & Yes & - & 2 & Yes & $0.75 \lambda_{0}$ \\
\hline [13] & Fractal load and DGS & $17.6 \times 17 \times 1$ & $16 \mathrm{~dB}$ & Narrow & Single & Yes & No & 2 & Yes & $0.22 \lambda_{0}$ \\
\hline [14] & U-Shaped Resonator & $24.25 \times 18.2 \times 1.6$ & $10 \mathrm{~dB}$ & Narrow & Single & Yes & Yes & 2 & Yes & $0.6 \lambda_{0}$ \\
\hline [15] & I-Shaped Resonator & $18.35 \times 30 \times 1.58$ & $30 \mathrm{~dB}$ & Narrow & Single & Yes & Yes & 2 & Yes & $0.45 \lambda_{0}$ \\
\hline [16] & W/g MTM & $40.34 \times 40.34 \times 0.76$ & $18 \mathrm{~dB}$ & Narrow & Single & Yes & No & 2 & Yes & $0.093 \lambda_{0}$ \\
\hline$[17]$ & Ground Slot & $15.5 \times 15.5 \times 0.8$ & $40 \mathrm{~dB}$ & Narrow & Single & Yes & Yes & 2 & Yes & $0.23 \lambda_{0}$ \\
\hline [18] & SCSRR & $20 \times 8 \times 0.8$ & $10 \mathrm{~dB}$ & Narrow & Single & Yes & Yes & 2 & Yes & $0.25 \lambda_{0}$ \\
\hline [19] & SCSRR & $15 \times 15 \times 1.27$ & $14.6 \mathrm{~dB}$ & Narrow & Single & Yes & Yes & 2 & Yes & $0.125 \lambda_{0}$ \\
\hline [20] & Compact EBG & $22 \times 22 \times 1.27$ & $17 \mathrm{~dB}$ & Narrow & Single & Yes & Yes & 2 & Yes & $0.8 \lambda_{0}$ \\
\hline [21] & Meander line & $46.82 \times 38.96 \times 1.5$ & $10 \mathrm{~dB}$ & Narrow & Single & Yes & No & 2 & Yes & $0.055 \lambda_{0}$ \\
\hline [22] & UC-EBG & $24.8 \times 24.6 \times 1.59$ & $14 \mathrm{~dB}$ & Narrow & Single & Yes & Yes & 2 & Yes & $0.5 \lambda_{0}$ \\
\hline [23] & EBG & $78.26 \times 78.26 \times 2.54$ & $10 \mathrm{~dB}$ & Narrow & Single & Yes & Yes & 2 & Yes & $0.5 \lambda_{0}$ \\
\hline [24] & EBG & $35 \times 35 \times 1.6$ & $5 \mathrm{~dB}$ & Medium & Single & Yes & - & 2 & Yes & $0.6 \lambda_{0}$ \\
\hline [25] & EBG & - & $13 \mathrm{~dB}$ & Medium & Single & Yes & Yes & 2 & Yes & $0.5 \lambda_{0}$ \\
\hline [26] & EBG and DGS & $17.62 \times 17.62 \times 1.143$ & $16 \mathrm{~dB}$ & Narrow & Single & Yes & No & 2 & Yes & $0.6 \lambda_{0}$ \\
\hline [27] & EBG & $27.5 \times 20 \times 2$ & $4 \mathrm{~dB}$ & Narrow & Single & Yes & Yes & 2 & Yes & $0.84 \lambda_{0}$ \\
\hline [28] & Slotted meander-line & $16.86 \times 16.86 \times 1.6$ & $16 \mathrm{~dB}$ & Narrow & Single & Yes & Yes & 2 & No & $0.11 \lambda_{0}$ \\
\hline [29] & W/g MTM & $25.35 \times 21 \times 1.43$ & $20 \mathrm{~dB}$ & Narrow & Single & Yes & No & 2 & Yes & $0.125 \lambda_{0}$ \\
\hline This work & Slots & $25 \times 20 \times 1.6$ & $>26 \mathrm{~dB}$ & Wide $(>23 \%)$ & Four & No & No & 4 & No & $0.37 \lambda_{0}$ \\
\hline
\end{tabular}




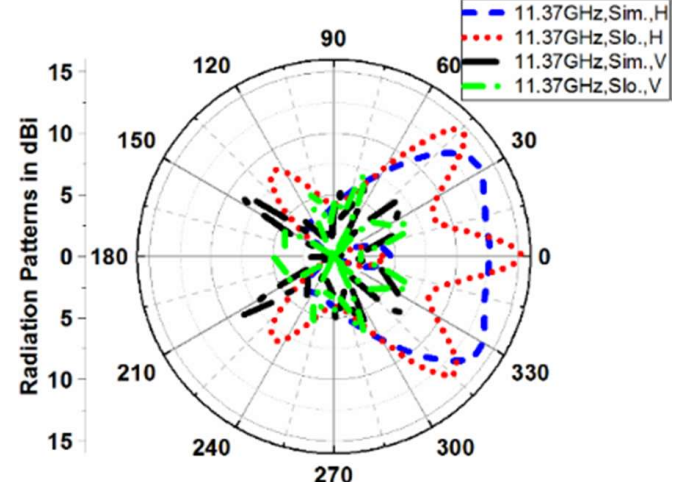

(a)

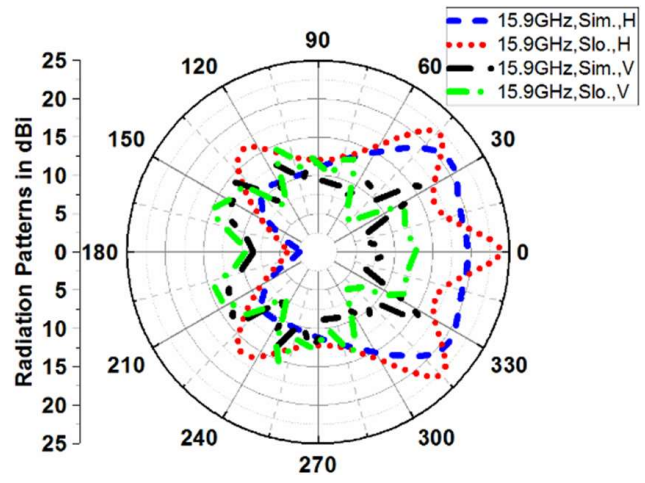

(b)

Figure 5. Radiation patterns of the simple reference (sim.) and proposed slotted (slo.) array antennas in the horizontal $(\mathrm{H})$ and vertical (V) planes at (a) $11.37 \mathrm{GHz}$ and (b) $15.9 \mathrm{GHz}$.

\section{Conclusions}

A simple technique is demonstrated that shows reduction in mutual coupling between adjacent radiating elements, which also allows the edge-to-edge gap between adjacent elements in an array to be reduced. This should enable beam-scanning over a larger angle in MIMO systems. This was achieved by embedding different lengths of slots near the periphery of the patch antenna. The resulting antenna array exhibits significantly improved isolation between neighbouring patch elements and gain performance over a narrower angular direction.

Author Contributions: Writing: Original draft preparation was made by M.A.; Supervisor and Project Administration, E.L.; Funding Acquisition, R.A.-A.; For other cases, all authors have participated.

Funding: This work is partially supported by innovation programme under grant agreement H2020-MSCAITN-2016 SECRET-722424 and the financial support from the UK Engineering and Physical Sciences Research Council (EPSRC) under grant EP/E022936/1.

Conflicts of Interest: The authors declare no conflict of interest.

\section{References}

1. Hung, H.-S.; Lu, H.-Y.; Cheng, Y.-H. A low-complexity genetic algorithm for joint antenna selection and power allocation in hybrid STBC-SM MIMO systems. Wirel. Pers. Commun. 2016, 88, 305-318. [CrossRef]

2. Subhashini, J.; Bhaskar, V. Spectrum efficiency evaluation with multiuser scheduling and MRC antenna diversity with effects of combining errors for Rayleigh fading channels with feedback. Wirel. Pers. Commun. 2015, 83, 791-810. [CrossRef]

3. Tseng, S.-M.; Wang, S.-H. Distributed quasi-orthogonal space time block code for four transmit antennas with information exchange error mitigation. KSII Trans. Internet Inf. Syst. 2013, 7, 2411-2429.

4. Malviya, L.; Panigrahi, R.K.; Kartikeyan, M.V. MIMO antennas with diversity and mutual coupling reduction techniques: a review. Int. J. Microw. Wirel. Technol. 2017, 9, 1763-1780. [CrossRef]

5. Xiao, S.; Liu, C.; Wang, R.; Wang, B. Wide-angle scanning planar phased array antenna. In Proceedings of the 2016 IEEE International Conference on Microwave and Millimeter Wave Technology (ICMMT), Beijing, China, 5-8 June 2016.

6. Hikage, T.; Omiya, M.; Itoh, K. Performance evaluation of cavity-backed slot antennas using the FDTD technique. In Proceeding of the IEEE Antennas and Propagation Society International Symposium, Salt Lake City, UT, USA, 16-21 July 2000; pp. 1484-1487.

7. Vaughan, M.J.; Hur, K.Y.; Compton, R.C. Improvement of microstrip patch antenna radiation patterns. IEEE Trans. Antennas Propag. 1994, 42, 882-885. [CrossRef]

8. Xiao, S.; Tang, M.C.; Bai, Y.Y.; Gao, S.; Wang, B.-Z. Mutual coupling suppression in microstrip array using defected ground structure. IET Microw. Antennas Propag. 2011, 5, 1488-1492. [CrossRef]

9. Abdalla, M.A.; Ibrahim, A.A. Compact and closely spaced meta-material MIMO antenna with high isolation for wireless applications. IEEE Antennas Wireless Propag. Lett. 2013, 12, 1452-1455. [CrossRef] 
10. Dimitrios, K.N.; Traianos, V.Y. Compact split-ring resonator-loaded multiple-input-multiple-output antenna with electrically small elements and reduced mutual coupling. IET Microwaves Antennas Propag. 2013, 7, 421-429.

11. Abushamleh, S.; Al-Rizzo, H.; Abosh, A.; Kishk, A.A. Mutual coupling reduction between two patch antennas using a new miniaturized soft surface structure. In Proceedings of the 2013 IEEE Antennas and Propagation Society International Symposium (APSURSI), Orlando, FL, USA, 7-13 July 2013; pp. 1822-1823.

12. Yang, F.; Rahmat-Samii, Y. Microstrip antennas integrated with electromagnetic band-gap (EBG) structures: A low mutual coupling design for array applications. IEEE Trans. Antennas Propag. 2003, 51, 2936-2946. [CrossRef]

13. Yang, X.; Liu, Y.; Xu, Y.-X.; Gong, S.-X. Isolation enhancement in patch antenna array with fractal UC-EBG structure and cross slot. IEEE Antennas Wirel. Propag. Lett. 2017, 16, 2175-2178. [CrossRef]

14. Islam, M.T.; Alam, M.S. Compact EBG structure for alleviating mutual coupling between patch antenna array elements. Prog. Electromagn. Res. 2013, 137, 425-438. [CrossRef]

15. Ghosh, C.K.; Parui, S.K. Reduction of mutual coupling between E-shaped microstrip antennas by using a simple microstrip I-section. Microw. Opt. Technol. Lett. 2013, 55, 2544-2549. [CrossRef]

16. Qamar, Z.; Park, H.-C. Compact waveguided metamaterials for suppression of mutual coupling in microstrip array. Prog. Electromagn. Res. 2014, 149, 183-192. [CrossRef]

17. OuYang, J.; Yang, F.; Wang, Z.M. Reduction of mutual coupling of closely spaced microstrip MIMO antennas for WLAN application. IEEE Antennas Wirel. Propag. Lett. 2011, 10, 310-312. [CrossRef]

18. Zhu, F.G.; Xu, J.D.; Xu, Q. Reduction of mutual coupling between closely packed antenna elements using defected ground structure. Electron. Lett. 2009, 45, 601-602. [CrossRef]

19. Suwailam, M.M.B.; Siddiqui, O.F.; Ramahi, O.M. Mutual coupling reduction between microstrip patch antennas using slotted-complementary split-ring resonators. IEEE Antennas Wirel. Propag. Lett. 2010, 9, 876-878.

20. Shafique, M.F.; Qamar, Z.; Riaz, L.; Saleem, R.; Khan, S.A. Coupling suppression in densely packed microstrip arrays using metamaterial structure. Microw. Opt. Technol. Lett. 2015, 57, 759-763. [CrossRef]

21. Farsi, S.; Schreurs, D.; Nauwelaers, B. Mutual coupling reduction of planar antenna by using a simple microstrip U-section. IEEE Antennas Wirel. Propag. Lett. 2012, 11, 1501-1503. [CrossRef]

22. Ghosh, J.; Ghosal, S.; Mitra, D.; Chaudhuri, S.R.B. Mutual coupling reduction between closely placed microstrip patch antenna using meander line resonator. Prog. Electromagn. Res. Lett. 2016, 59, 115-122. [CrossRef]

23. Farahani, H.S.; Veysi, M.; Kamyab, M.; Tadjalli, A. Mutual coupling reduction in patch antenna arrays using a UC-EBG superstrate IEEE Antennas Wirel. Propag. Lett. 2010, 9, 57-59.

24. Rajo-Iglesias, E.; Quevedo-Teruel, O.; Inclan-Sanchez, L. Mutual coupling reduction in patch antenna arrays by using a planar EBG structure and a multilayer dielectric substrate. IEEE Trans. Antennas Propag. 2008, 56, 1648-1655. [CrossRef]

25. Al-Hasan, M.J.; Denidni, T.A.; Sebak, A.R. Millimeter wave compact EBG structure for mutual coupling reduction applications. IEEE Trans. Antennas Propag. 2015, 63, 823-828. [CrossRef]

26. Exposito-Dominguez, G.; Fernandez-Gonzalez, J.M.; Padilla, P.; Sierra-Castaner, M. Mutual coupling reduction using EBG in steering antennas. IEEE Antennas Wirel. Propag. Lett. 2012, 11, 1265-1268.

27. Yu, A.; Zhang, X. A novel method to improve the performance of microstrip antenna arrays using a dumbbell EBG structure. IEEE Antennas Wirel. Propag. Lett. 2003, 2, 170-172.

28. Alsath, M.G.; Kanagasabai, M.; Balasubramanian, B. Implementation of slotted meander line resonators for isolation enhancement in microstrip patch antenna arrays. IEEE Antennas Wirel. Propag. Lett. 2013, 12, 15-18. [CrossRef]

29. Yang, X.M.; Liu, X.G.; Zhu, X.Y.; Cui, T.J. Reduction of mutual coupling between closely packed patch antenna using waveguide metamaterials. IEEE Antennas Wirel. Propag. Lett. 2012, 11, 389-391.

(C) 2018 by the authors. Licensee MDPI, Basel, Switzerland. This article is an open access article distributed under the terms and conditions of the Creative Commons Attribution (CC BY) license (http:/ / creativecommons.org/licenses/by/4.0/). 